\title{
Management of Staff and Students Living with HIV and AIDS in a South African Rural-Based University
}

\author{
Azwihangwisi Helen Mavhandu-Mudzusi \\ Department of Health Studies, Faculty of Human Sciences, University of South Africa, \\ P.O Box 392, Pretoria, 0003, South Africa \\ Telephone: +27 12 4292055, E-mail: mmudza@unisa.ac.za
}

KEYWORDS HIV/AIDS. Rural-Based University. Treatments. University Population

\begin{abstract}
Human Immunodeficiency Virus and Acquired Immunodeficiency Syndrome (HIV/AIDS) is making its toll in South African institutions of higher education. Studies revealed that several students and staff became ill and some died in patterns that signal HIV and AIDS-related conditions. The study aim was to explore how the staff and students living with HIV and AIDS are managed at a South-African rural-based university. The study used Interpretative Phenomenological Analysis (IPA) approach as a methodology. In-depth interviews were conducted with19 participants composed of staff and students living with HIV and AIDS and other university staff involved in the provision of care to this population. Data were analysed using IPA framework for data analysis.One superordinate theme "inadequate planning to address the need for managing staff and students living with HIV and AIDS on the campus” emerged from data analysed. This theme had four sub-themes: persisting stigma and discrimination, lack of confidentiality, inadequate treatment, care and support. This study recommends the development of a contextually relevant HIV/AIDS care management model for a South African rural-based university.
\end{abstract}

\section{INTRODUCTION}

HIV/AIDS is a global health concern. It is documented that HIV/AIDS affects the physical, social, economic and psychological wellbeing of individuals, institutions, community and the systems of government (National Agency for the Control of AIDS 2009). In order to address this HIV/AIDS pandemic, several organisations such as the Joint United Nations Programme on HIV and AIDS (UNAIDS) the United Nations (UN) and the World Health Organisation (WHO) are fully involved developing strategies to address this pandemic. One of such strategies is UNAIDS vision which focus on achieving among others, Zero new HIV and TB infections including infections from mother to child, Zero preventable death related to HIV and TB and Zero discrimination associated with this conditions (Schwartlander et al. 2011; UNAIDS 2011; UN 2013). In response to this global approach, South African government through South African National AIDS Council (SANAC) developed a National Strategic Plan for HIV/AIDS , STI and TB in 2007 and revised the same in 2011 (Shisana et al. 2014). The National Strategic plan had four major goals namely: (1) reduction of new HIV infections by at least $50 \%$, (2) initiating $80 \%$ of patients who are eligible to Antiretroviral treatments (3) ensuring that $70 \%$ of those on treatment remain on treatment and alive five years after initiation of that treatment and (4) reducing the number of TB infections and deaths from TB. All the above goals should be achieved by the year 2015 (SANAC 2011).

HIV prevention, treatment, care and support is considered as part of evidence based intervention with positive results in reduction of new HIV infections and improving the quality of lives of people living with HIV and AIDS (National Department of Health (NDOH) 2013; Shisana et al. 2009).To ensure that eligible patients access antiretroviral treatments, South Africa had increased facilities offering antiretroviral treatments and resort to Nurse initiated antiretroviral treatments (SANAC 2011). Increase in the number of people on Antiretroviral treatments has led to reduction in HIV/AIDS related death and increase the life expectancy (Johnson et al. 2013; UNAIDS 2012). Ensuring that eligible people are put on Antiretroviral treatments has benefits to uninfected people as it also prevent the risk of spreading infections (SANAC 2011).

SANAC also emphasise on ensuring that people living with HIV and AIDS are receiving proper treatment, care and support (SANAC 2011). Care of people living with HIV and AIDS involve ensuring quality prevention, early diagnosis and management of opportunistic infections and access to quality treatment and support services. Those support services should 
focus on ensuring physical and mental health (SANAC 2011). Another important aspect of care and support is ensuring that people who are living with HIV and AIDS remain in the system and also adhering to treatment. This may be made possible through integrating HIV and TB services and provision of the treatments for such at Primary Health clinics (SANAC 2011; WHO 2014). This will reduce number of patients who get lost in the system between referral from Primary health centres to other institutions (SANAC 2011). Another important component of care is assessment of baseline CD4 cell counts which is important in stratifying risk and guiding clinical decisions about starting prophylaxis and screening for opportunistic infections (WHO 2014). Another important strategy for addressing HIV and AIDS is addressing social aspects which exacerbate this condition such as poverty through activities such as provision of food, shelter and providing access to health and social services (SANAC 2011). Another strategy is improving access of males to health care services as it documented that very few males use the normal health care centers (Shisana et al. 2014; van Rooyen et al. 2013).

Despite all those strategies, South Africa showed an increase in the number of people living with HIV and AIDS. In 2012, this country had 6.4 million people living with HIV and AIDS which is 1.2 million higher than 2008 results which indicated a total of 5.2 million people (Shisana et al. 2014). The high incidence of HIV is among young women aged 15-24 years. This is an issue of concern not only to the country, but also to the institutions of Higher education as this age range include the ages of majority of university students. HIV prevalence is also reported to be high in rural informal residential area according to Shisana et al. (2014). Which is the place where most of the students in Rural-based Universities are staying. Literature indicates that universities are among the institutions that are also affected by HIV/AIDS scourge (Higher Education HIV/AIDS Programme (HEAIDS) 2010). Phaswana-Mafuya and Peltzer (2006) indicate that HIV/AIDS leads to a loss of skilled workers and reduced throughput for skilled graduates. These situations compromise the value of education and the worth of institutions of Higher Education. The situation in the South African universities indicates that there is a need to plan for managing Staff and students living with HIV and AIDS. This was confirmed by the Higher Education HIV/AIDS Programme (HEAIDS 2010) report of survey conducted in the South African universities, showing the highest HIV prevalence rate amongst service staff (12.2\%), followed by administrative staff (4.4\%) and students (3.4\%). Academic staff were found to have the lowest overall HIV prevalence (1.5\%). These results indicate that there is a need to manage staff and students living with HIV and AIDS in South African universities. Proper management of students and staff living with HIV and AIDS will lead to their improved quality of life. Improved quality of life will ensure that staff remains productive and students graduate being healthy. Statistics of a South African Rural-based University which is the study site of this research indicate an increase in the number of students and staff who tested HIV positive from 12 in 2004 to 52 in 2011. (Voluntary Counselling and Testing Register 2004-2012). Although statistics were not available (because the majority are using hospitals and private practitioners for treatment), the university HIV/AIDS Unit reports an increase in HIV/AIDS related illnesses and deaths of students and staff. The aim of this study was to explore how the staff and students living with HIV and AIDS are managed at a South-African rural-based university.

\section{METHODOLOGY}

\section{Design}

To date, less empirical attention has been directed towards examining the management of staff and students living with HIV and AIDS at South African rural-based universities. Phenomenological methodologies are considered effective for studying under researched and poorly understood phenomena (Smith et al. 2009). The researcher opted to use Interpretative Phenomenological Analysis approach to explore how the staff and students living with HIV and AIDS are managed at a South-African Rural-based University. This phenomenological approach recognizes that the meanings people attribute to their experiences can be understood in the socio-cultural contexts in which they are experienced (Langdridge 2007; Smith et al. 2009). 


\section{Sampling and Participants}

The South African Rural-based University where the study was conducted was established during the 'apartheid era' to cater for the tertiary educational needs of an ethnic groups residing in one of the former homelands (Nkomo 2007). Majority of the students in that university are from the poorest provinces of South-Africa. The university also accommodates students from other countries in sub-Saharan Africa. These students together with the university staff constituted the study population. A non-probability purposive approach was used to recruit participants. Participants were included based on their HIV positive status or their direct involvement in the management of staff and students living with HIV and AIDS on campus. The sample size was 19 participants and was determined by category saturation. The sample comprise: (1) two Campus Health personnel responsible for providing services to staff and students living with HIV and AIDS, (2) three Health promoters who are People living with HIV and AIDS, employed on campus to openly, disclose their HIV status in order to promote HIV Counselling and Testing and positive living with HIV among university community); (3) ten students and fourstaff members living with HIV and AIDS.

\section{Data Collection and Analysis}

Ethical clearance was granted by the Ruralbased University health, Safety and Research Ethics Committee. The participants were informed about the research purpose. Their voluntary participation was obtained through signing a consent form. The participants' right to confidentiality was maintained by using pseudonyms. Data were collected using semi-structured interviews. All interviews stemmed from the following central question: 'How are the university managing staff and students living with HIV and AIDS? 'Probes, minimal encouragers and follow-up questions guided by the interview schedule were used to enhance the richness of personal accounts (Smith 2005). Each interview lasted for about 45 to 60 minutes and was audio taped. Field-notes were compiled to capture and describe the non-verbal cues observed during interviews. Interpretive phenomenological analysis framework was followed for data analysis. The analysis was carried out in parallel with the interviews, and was conducted iteratively throughout the interview period (January-March 2012) until category saturation was achieved. The interviews were conducted in English which is not the first language of the participants. An independent analyst analysed the transcripts and the results were compared with initial results to ensure credibility, dependability and transferability of data (Polit and Beck 2012).

\section{RESULTS}

One superordinate theme emerged from the analysis: Inadequate planning for managing staff and students living with HIV and AIDS on the University campus. This theme is composed of four sub-themes. Each of the sub-themes is made of third order categories, which are illustrated by excerpts from participants 'narratives to enhance understanding of discussions presented. The initials "HCP" (Health Care Personnel), "HP” (Health Promoter), "STA" (staff) and "STU" (students) are used in this paper to indicate the position/status of participants.

\section{Superordinate Theme: Inadequate planning}

The most articulated HIV/AIDS management issues that emerged during the interviews were stigmatisation and discrimination, confidentiality, treatment, care and support of staff and students living with HIV and AIDS. Participants showed that these issues are interrelated and interdependent and therefore impact on each other. Results indicate that the Rural-based University has inadequately planned for managing staff and students living with HIV and AIDS, which was evidenced by the presence of stigma and discrimination, lack of confidentiality, and inadequate treatment and support of staff and students living with HIV and AIDS.

\section{The Presence of Stigma and Discrimination}

Stigma and discrimination are some of the factors which negatively affect the quality of life of staff and students living with HIV and AIDS. The views of participants differ regarding the aspects of stigma and discrimination. Recipients of the services were of the opinion that they felt stigmatised by the services offered. In contrast, the service providers reported that 
their services were non-stigmatising. A health care professional mentioned that people seeking health care service are treated in the same manner without segregation.

We manage the HIV positive people as any other student who is coming to the clinic without any discrimination or segregation (HCP).

Although the campus health personnel felt that they are offering non-discriminatory services, participants living with HIV and AIDS felt they were being stigmatised and discriminated against.

Stigma and discrimination is very high on campus toward HIV-positive people by both students and staff (HP).

\section{Inadequate Assurance of Confidentiality}

Confidentiality was considered essential for adequate management of HIV and AIDS. However, participants had different views about its maintenance in a rural based university. Other participants, especially the campus health personnel felt that there was adequate consideration for confidentiality of staff and students living with HIV and AIDS

If the clients are referred from the HIV/AIDS unit where they are tested for HIV, to Campus Health Clinic for treatment and refuse to disclose their HIV status, we do not force them. But if they disclose, we ensure that it remain confidential (HCP).

However, staff and students living with HIV and AIDS alluded that confidentiality is not maintained at all, due to the infrastructural challenges.

There is no confidentiality because from the office of the Health promoter who is offering pre- and post-test counselling to the office of the HIV coordinator's office who performs the HIV test, we use the same entrance were we pass through people waiting for HIV Counselling and Testing. These people are able to checktested client's facial expression and the length of time spent in the HIV/AIDS coordinator's office and make conclusion about the HIV status (STU).

The normal requirement for HCT service is that it should be offered in a counselling room where there is maximum privacy. This is ensured by having two separate doors where people who are waiting for HCT would not have contact with those who have just received their HIV results. This is to prevent the facial expressions of test- ed person from revealing the test outcome to others.

\section{Insufficient Treatment, Care and Support}

Participants indicated that although staff and students living with HIV and AIDS were given support, there was apparently no adequate planning for comprehensive provision of treatment, care and support. Discussions on care, support and treatment focused on monitoring of CD4 cell count, treatment of opportunistic infections, provision of antiretroviral treatments (ARVs), and payment of consultation fees for HIV/AIDS care services, nutritional and psychosocial support.

\section{Monitoring of CD4 Cell Count}

The CD4 cell count determines the immune status of a person living with HIV and AIDS. It is also used as a determining factor for initiating (ARVs), and/or changing the ART regime. People living with this condition cannot be managed properly without monitoring their CD4 cell count (SANAC 2007, 2011). The university was reported to be monitoring the CD4 cell counts of staff and students living with HIV and AIDS at regular intervals.

The HIV/AIDS units nurse checks our CD4 counts every six months (STA).

\section{Poor Management of Opportunistic Infections}

The presence of stigma and discrimination also affect the management of opportunistic infections. Participants reported poor treatment of staff and students living with HIV and AIDS by some of the Campus Health personnel when seeking treatments for opportunistic infections. Their feelings were expressed with deep levels of emotional responses.

Some campus health staff are reluctant to assist a person suffering from HIV and AIDS related conditions (HP).

Results indicate reluctance by some campus health staff in the management of staff and students living with HIV and AIDS. This was manifested by poor management of staff and students suffering from opportunistic infections, which for some participants was viewed as a sign of persistence stigma and discriminatory practices.

I visited the clinic several times complaining of coughing, every time the nurse just gave 
me same treatment without even touching me. When I visited the doctor because I was not improving, the doctor told me that I have TB (STA).

This situation may contribute to the reluctance of staff and students living with HIV and AIDS to seek treatment. Doing so may result in complications of opportunistic infections such as TB and its spread on campus.

\section{Lack of ARVs on Campus}

The University was not offering ARVs, but staff and students who need ARVs were referred to the nearest hospital and health centres for such treatments. This was an issue of concern to some of the participants:

The university clinic does not provide ARVs but referred us to the nearest hospital which is always full of people from all over the country.

Results further show that staff and students living with HIV and AIDS were sceptical about being treated in the nearby hospital due to overcrowding. Thus, sometimes missing lessons or work hours. It was also a threat to confidentiality of the HIV status of staff and students as they may meet some people from their community in the hospital. Participants living with HIV and AIDS suggested the need for the clinic to offer ARVs.

My motivation is that the Campus Health clinic should offer ARVs free of charge. There are a lot of people I know who are now very sick but they are afraid of going to the hospital for treatment and cannot afford to pay the private doctors for treatment (HP).

Participants view issues of not having ARVs on the campus as a lack of commitment by the Management Team to people living with HIV and AIDS on campus:

HIV positive people are not considered by the university management because if they were considered, ARVs would be issued on campus (HP).

\section{Payment of Consultation Fees for HIV/AIDS Services}

Findings indicate that people living with HIV and AIDS were treated free of charge in the South African government health care facilities. This was not the case in the Campus Health Clinic. This issue of payment in the campus health distressed some of the participants living with HIV and AIDS who felt that they should also be treated free of charge.

I think that staff and students living with HIV and AIDS must not pay. It's a human right issue. I don't think they should pay for any treatment at the campus Health Clinic if people are not paying for contraceptives and HIV test (STU).

However, the Campus Health Care personnel were not in agreement with the issue of free treatment of staff and students living with HIV and AIDS.

Why should HIV positive people be treated in a special way? They must pay for consultation fee like all other people who visit the Campus Health clinic. Otherwise all other students will get infected in order to get free treatment (CHP).

Results also indicated a lack of clear policies and guidelines regarding payment of consultation fees.

"Issues of payment are not clear and I am not sure if there is any policy because with me if I have to pay every time I go and consult, it will be too expensive for me.So I pay only when I have money to do so (HP).

The situation where staff and students living with HIV and AIDS are treated at the Campus Health clinic only when they have money may have detrimental impact on their health. Taking into consideration the socio-economic statuses of majority of students in that university, some may end up not accessing health care services or finding other means of having money including engagement in transactional-sex. Such sexual behaviours may results in the possibility of spreading HIV infection. The other scenario may be just waiting until such time they get money while the condition is gradually deteriorating, or even spreading to other people if they are suffering from infectious opportunistic infections such as Tuberculosis.

\section{Inconsistent Supply of Nutritional Support}

Results indicated that staff and students living with HIV and AIDS were offered different types of food supplements.

We obtain food supplements from the HIV/ AIDS unit. The supplements we receive include energy drinks, milk shakes and soft porridge (STU). 
Although some participants mentioned that they were given food supplements, findings further indicated that there was no consistency in their supply:

Food supplements ordered are not adequate for all staff and students living with HIV and AIDS. This is because of limited funds. There were occasions when we had no food supplement (HP).

In-consistency in the supply of food supplements was a concern as some staff and students living with HIV and AIDS cannot afford to buy nutritional food required to boost their immunity. Food supplements were the sole meal for some of the participants. So, the absence of this was a huge concern as ARVs and Anti-Tuberculosis treatments are not supposed to be taken in an empty stomach.

\section{Limited Involvement to Support Measures}

The South African rural based university offered psychological support in the form of support groups and on-going counselling to staff and students living with HIV and AIDS.

We provide on-going counselling and support to HIV infected people through monthly support group meetings and weekly mini support groups (HP).

However, the support group meetings were attended only by female students living with HIV and AIDS.

I have never met any HIV positive staff member or male students in our support group meetings but only female students (STU).

Poor involvement of staff and students living with HIV and AIDS in the support group meetings may be related to fear of stigma and discrimination or threat to confidentiality. This is because the majority of this population were not willing or ready to disclose their status to anybody, including those who are also living with HIV and AIDS. This might also be the rationale for their reluctance to visit the nearest hospital for ARVs.

\section{DISCUSSION}

This study explored how the staff and students living with HIV and AIDS are managed at a South-African rural-based university. One superordinate theme "inadequate planning to address the need for managing staff and students living with HIV and AIDS on the campus" emerged from data analysed. Inadequate planning as reported continuously by participants of this study is in contrast with the requirements by SANAC (2011) which advocate for involvement of all sectors in South Africa in prevention of new HIV infections and provision of care and support for people living with HIV and AIDS. SANAC (2011) also mentioned that management of HIV/AIDS should be positioned as an investment in the health of South African people and their democracy. Inadequate planning for managing staff and students living with HIV and AIDS was evidenced by the presence of stigma and discrimination, lack of confidentiality, inadequate treatment, care and support of staff and students living with HIV and AIDS.

Participants for this study had contrasting views regarding stigma and discrimination. Recipients of the services were of the opinion that they felt stigmatised by the services offered. In contrast, the service providers reported that their services were non-stigmatising. A health care professional mentioned that people seeking health care service are treated in the same manner without segregation. These findings are in line with findings by Shisana (2014) and requirements by SANAC (2011). However, staff and students living with HIV and AIDS felt that they were stigmatised. Stigma and discrimination are some of the factors which negatively affect the quality of life of staff and students living with HIV and AIDS. The presence of stigma and discrimination is defeating the UNAIDS and SANAC vision of Zero discrimination associated with this conditions (SANAC 2011: Schwartlander et al. 2011).

Apart from stigma and discrimination, this study highlighted the issues of confidentiality. As with the issues of stigma and discrimination, participants had different views about its maintenance in the Rural-based University. Campus health personnel felt that there was adequate consideration for confidentiality. In contrast, staff and students living with HIV and AIDS were of the view that confidentiality was not maintained. They point the structural defects as the main threat to confidentiality. This threat to confidentiality may hinder people from utilising the health care services with resultant deteriorating of health of staff and students living with HIV and AIDS. This structural issue may be the one which is hindering staff and male students from utilis- 
ing the services or attending support group meetings as reported by some participant. The aspects of structural challenges need to be addressed as recommended by some of the participants in this study and also in literature (SANAC 2011: van Rooyen et al. 2013).

Participants claimed that the Rural-based University was not providing treatment care and support to staff and students living with HIV and AIDS. In addition to HIV prevention, treatment, care and support were considered as part of evidence based intervention with positive results in reduction of new infections and improving the quality of lives of people living with HIV and AIDS (NDOH 2013; Shisana et al. 2009). The aspects which were considered important by participants were monitoring of CD4 cell count, treatment of opportunistic infections, provision of ARVs, payments of consultation fees, nutritional supplements and psychosocial support. Their requirements were in line with SANAC (2007, 2011) and WHO (2014). Participants was satisfied regarding the way in which the university staffs was monitoring the CD4 count of staff and students living with HIV and AIDS. Assessment of CD4 cell counts is important in determining the immunity status of people living with HIV and AIDS. It also guides the care and treatment required including initiation of clients to ARVs (WHO 2014).

Though results indicated proper monitoring of CD4 count, its purpose seemed to have been defeated by poor management of opportunistic infections some campus health personnel. It was further alluded that some health care professionals were sometimes providing treatment to staff and students living with HIV and AIDS without proper assessment and diagnosis. This practice is hazardous as it may contribute to complications of minor opportunistic infections and also unnecessary death from easily diagnosable and manageable opportunistic infections such as TB. Poor management of opportunistic infections is in contrast with recommendations by SANAC (2011) and WHO (2014) mentioning that care of people living with HIV and AIDS involve ensuring quality prevention, early diagnosis and management of opportunistic infections. As TB is the major HIV opportunistic-infection, its management is considered equally important to managing HIV, hence reducing the number of TB infections and deaths from TB is mentioned as one of the goals for the 2012-2016 National Stra- tegic Plan (SANAC 2011). Delayed diagnosis and treatment of TB is a health hazard to the university as the person infected will continue to spread the infection. This will be defeating UNAIDS vision of Zero new HIV and TB infections and Zero preventable death related to HIV and TB (Schwartlander et al. 2011; UN 2013).

This study reported that the Rural-based University was not offering ARVs to staff and students living with HIV. Those who were eligible to be initiated on treatment were referred to the nearest hospital and health centres. This was an issue of concern to some of the participants as they were sceptical about being treated in the nearby hospital due to overcrowding. This overcrowding made them to sometimes spend the whole day at the hospital. The aspect of not offering ARVs is in contrast with the recommendations by SANAC (2011) which advocate for initiation of all eligible patients to ARVs in Primary Health Centres. SANAC (2011) and WHO (2014) also emphasise the need for initiation of ARVs by professional nurses to ensure comprehensive services for patients living with HIV and AIDS. Issues of referral to other facilities made some staff and students living with HIV and AIDS to end up not receiving ARVs due to fear of the possibility of meeting people from their community in the hospital who may disclose their HIV status. Aspects of not accessing ARVs by eligible clients do not only affect the quality of life of infected clients but the university as a whole because, the sick students may have poor performance in class which will affect university graduations, while the sick staff will not be able to fulfil the mandate of the university of teaching and learning, research and community engagement directly (if the person is an academic) or indirectly if the person is administrative staff or service worker (Phaswana-Mafuya and Peltzer 2006). The participants viewed issues of not having ARVs on campus as a lack of commitment by the University Management Team to managing people living with HIV and AIDS. This allegation may not be fully denied considering the recommendations by several structures for the South African Universities to adequately manage HIV and AIDS (HEAIDS 2010; SANAC 2011).

Other thorny issue raised by the participants was payment of consultation fee. Participants had an opinion that they need to access all treatments from the Campus Health clinic free of 
charge as what was happening in other Primary Health Care settings. Based on the recommendations of staff and students living with HIV and AIDS, and also considering the socio-economic status of majority of staff and students in the rural based university, it was reasonable that the services be offered free of charge. This is also in line with literature advocating for accessible and affordable HIV/AIDS and TB services (SANAC 2011; WHO 2014; Shisana et al. 2014). However, the health care professionals had the view that offering free services to this population will be like a strategy for promoting other students and staff to be infected with HIV in order to also receive free treatment. This argument by health care personnel indicate ignorance regarding HIV and AIDS and the overall impact of mismanaged HIV and related opportunistic infections on the infected individuals and the impact it may have to the entire university.

Payment of fee was considered a stumbling block to access treatment especially because the majority of the students came from indigent families which cannot even afford to pay for their own meals. Some of this population was dependant on food supplements which were distributed in the HIV/AIDS unit. Such supply of food supplements was noted to be inconsistant. This may contribute to malnutrition, which does not only have a negative impact on treatment usage but it may also act as a contributory factor to wasting syndrome that is associated with exposure to opportunistic infections and rapid progression to AIDS stage. Lack of consistency in the provision of nutritional support is contrary to SANAC (2011) emphasising addressing social aspects which exacerbate HIV and AIDS such as poverty through strategies such as provision of food, shelter and providing access to health and social services (SANAC 2011).

Apart from physical support, staff and students living with HIV and AIDS requires psychological support. Though the University was offering counselling in the form of support groups, some students felt that it was not adequate. This was in contrast with the WHO (2014) which stresses the importance of on-going counselling as a means of emotional support and education to prevent and control HIV infection. On-going counselling and support is considered important aspect of care and support as it assist in ensuring that people who are living with HIV and AIDS remain in the health system and also adhering to treatment. Another aspects raised in this study is that the support groups are attended only by female students only, but fail to attract staff members and males living with HIV and AIDS. Non-attendance of male students to support group meetings is not unique to the Rural based university, but a national challenge. Hence there is recommendations in several literature for improving access of males to health care services (SANAC 2011; van Rooyen et al. 2013; WHO 2014).

\section{CONCLUSION}

The findings of this study indicate that a South African Rural-based University has inadequately planned for managing staff and students living with HIV and AIDS. This was evidenced by persisting stigmatisation and discrimination, lack of confidentiality and inadequate treatment, care and support of this population. Inadequate treatment care and support was shown by failure to offer antiretroviral treatment, inconsistent supply of nutritional support, inadequate ongoing counselling and payment of consultation fees for management of opportunistic infections.

\section{RECOMENDATIONS}

The findings of this study indicate a need for the development of a contextually relevant HIV/AIDS management model for a South African rural-based university the model should include aspects of proper planning, organising, leading and controlling for managing staff and students living with HIV and AIDS. Some of the aspects to be addressed in the model should be: access to ARVs on campus; maintaining confidentiality through infrastructure organisation; exemption of this population from payment of consultation fees on campus; continuous nutritional support. The support should include offering at least one meal per day for staff and students living with HIV and AIDS, but also including other students who have nutritional needs, ensuring maintenance of confidentiality and addressing stigmatization and discrimination. Care and support should extend to the immediate relatives of university community when need arise. The developed model should be aimed at improving the quality of life of staff and students living with HIV and AIDS and reduction of new HIV infection. 


\section{LIMITATIONS}

All participants for this study were females, and some of them were stationed in the HIV/ AIDS unit, being also co-responsible for rendering the service to other staff and students living with HIV and AIDS. The researcher was part of the university staff member which might have influenced the way participants responded during the interviews. These considerations indicate that although the present study identified notable patterns, the explanation of such patterns may require further investigation.

\section{REFERENCES}

HEAIDS 2010. HIV Prevalence and Related Factors. Higher Education Sector Study South Africa 20082009. Pretoria: HEAIDS.

Johnson LF, Mossong J, Dorrington RE, Schomaker M, Hoffmann CJ, Keiser O, et al. 2013. Life expectancies of South African adults starting antiretroviral treatment: Collaborative analysis of cohort studies. PLoS Med, 10: 1001418.

Langdridge D 2007. Phenomenological Psychology: Theory, Research and Method. Harlow, UK: Pearson Education.

National Agency for the Control of AIDS 2009. Federal Government of Nigeria. National policy on HIV/ AIDS. Nigeria: National Agency for the Control of AIDS.

National Department of Health 2013. The South African Antiretroviral Treatment Guidelines. March 2013. Pretoria: NDOH.

Nkomo M 2007. Rural based universities in South Africa. Albatrosses or potential nodes for sustainable development? International Journal of Sustainability in Higher Education, 8(2): 234-246.

Phaswana-Mafuya MN, Peltzer K 2006. Perceived HIV/ AIDS impact among higher education institutions in the Eastern Cape. South African Journal of Higher Education, 20(1):143-156.

Polit DF, Beck CT 2012. Nursing Research: Generating and Assessing Evidence for Nursing Practice. $8^{\text {th }}$
Edition. Philadelphia: JB Lippincott Williams and Wilkins.

SANAC 2007. HIV and AIDS and STI National Strategic Plan for South Africa 2007-2011. Pretoria: SANAC.

SANAC 2011. National Strategic Plan on HIV, STIs and TB 2012-2016. Pretoria: SANAC.

Schwartlander B, Stover J, Hallett T, Atun R, Avila C, Gouws E et al. 2011. Towards an improved investment approach for an effective response to HIV/ AIDS. Lancet, 377: 2031-2041.

Shisana O, Rehle T., Simbayi LC, Zuma Kooste S, Pillay-van Wyk V et al. 2009. South African National HIV Prevalence. Incidence and Communication Survey 2008: A Turning Tide among Teenagers? Cape Town: HSRC Press.

Shisana O, Rehle T, Simbayi LC, Zuma K, Jooste S, Zungu N, Labadarios D, Onoya D et al. 2014 South African National HIV Prevalence, Incidence and Behaviour Survey, 2012. Cape Town: HSRC Press.

Smith JA 2005. Semi-structured interviewing and qualitative analysis. In: JA Smith, R Harre. L van Langenhove (Eds.): Rethinking Methods in Psychology, London: Sage, pp. 9-26.

Smith JA, Flowers, P, Larkin M 2009. Interpretive Phenomenological Analysis: Theory, Method and Research. London: Sage.

UNAIDS 2011. Issues Brief. UNAIDS: Geneva.

UNAIDS 2012. UNAIDS Report on the Global AIDS Epidemic 2012. Geneva: UNAIDS.

UN 2013. We Can End Poverty: Millennium Development Goals and Beyond 2015. Fact Sheet. UN Department of Public Information

Van Rooyen H, McGrath N, Chirowodza A, Joseph P, Fiamma A, Gray G, Richter L, Coates T 2013. Mobile VCT: Reaching men and young people in urban and rural South African Pilot Studies (NIMH Project Accept, HPTN 043). AIDS and Behavior, 17(9): 2946-2953.

Voluntary Counselling and Testing Register 2004-2012. Rural Based University HIV/AIDS Unit HIV counselling and Testing Register. Rural Based University: South Africa.

World Health Organisation 2014. Supplement to the 2013 Consolidated Guidelines on the Use of Antiretroviral Drugs for Treating and Preventing HIV Infection. Recommendations for a Public Health Approach. Geneva: WHO. 